УДК 553.3:553.2

\title{
ДИВЕРГЕНЦИЯ И КОНВЕРГЕНЦИЯ В РУДНОФОРМАЦИОННОМ АНАЛИЗЕ
}

\author{
А. А. Сидоров, А. В. Волков \\ ФГБУН Институт геологии рудных месторождений, петрографии, минералогии \\ и геохимии РАН, г. Москва \\ E-mail: kolyma@igem.ru; tma2105@mail.ru
}

\begin{abstract}
В рудноформационном анализе (РА) дивергентные явления распространены не менее, чем конвергентные. В отличие от биологии, в РА дивергенция означает принципиальное разнообразие рудноформационных рядов. Таким образом, ряды авторы считают дивергентными, а месторождения в них, с элементами сходства по РТ-условиям отложения минеральных ассоциаций, объединяют в группы с различной степенью конвергентности (малых, умеренных и больших глубин и температур). Каждый ряд возглавляет базовая формация, в которой отражены элементы рядовых месторождений, нередко в виде стадийных минеральных ассоциаций. На основе этой концепции могут быть предложены прогностические ряды месторождений не только в металлогенических провинциях, но и в пределах отдельных рудных районов.
\end{abstract}

Ключевые слова: дивергенция, конвергенция, рудная формация, рудные месторождения, ряд, генезис, прогноз.

DOI: $10.34078 / 1814-0998-2019-2-22-28$

\section{ВВЕДЕНИЕ}

В любой отрасли естественных наук систематики* исследуемых объектов имеют первостепенное значение. Успехи отрасли в значительной мере зависят от удачности систематик этих объектов. Опыт удачных и неудачных систематик столь огромен, что один из авторитетных журналов РАН - «Доклады АН» не принимает классификационные статьи, опасаясь, по-видимому, «утонуть в море» бесчисленных систематик. Но если анализировать упомянутый опыт, то нетрудно обнаружить, что успех и эффективность систематик зависели, прежде всего, от степени однородности, подобия, иерархичности объектов, их генетических свойств и, разумеется, от степени проникновения исследователя в природу систематизируемых объектов.

Недосягаемым примером удачной и глубоко генетической классификации служит Периодическая система элементов Д. И. Менделеева, определившая основу современного учения о строении вещества. Открытие периодов и групп не только имело прогностическое значение при

(C) Сидоров А. А., Волков А. В., 2019

*Систематики и классификации в геологии рудных месторождений обычно принимаются как близкие понятия или даже синонимы. выявлении новых элементов, но и оказало существенное влияние на развитие научной методологии в целом. Заметим, что все это было сделано без применения какого-либо сложного физикоматематического аппарата, хотя последний позднее успешно развивал глубины этой гениальной классификации.

Термин «формация» в геологии существует уже более 250 лет. В решении второй сессии Международного геологического конгресса в 1881 г. настоятельно рекомендовалось развивать формационный анализ. Для чего следовало отказаться от употребления термина «формация» в стратиграфическом смысле, адекватного содержанию свиты или толщи осадочных и вулканогенных пород; в особенности эта рекомендация относилась к американским геологам. В отечественной литературе наибольшее признание получило определение формации, данное Н. С. Шатским (1964), который в его основу положил представление о парагенезисе горных пород и их сонахождении. Однако с 90-х гг. прошлого столетия термином «формация» перестали пользоваться многие геологи. В частности, В. Е. Хаин и М. Г. Ломизе заявили, что «в noследнее время понятие формации... вытесняется понятием литодинамических (или литогеодинамических) комплексов, под которыми понимаются комплексы горных пород, характерные 
для определенных геодинамических обстановок, например, гранитные батолиты для орогенов или глауконитовые пески для платформ» (1995. C. 10). Но геологические формации состоят именно из комплексов горных пород. И поэтому при желании и в соответствии с элементарной логикой выделение литодинамических комплексов можно рассматривать как развитие формационного анализа.

Рудной формащией в соответствии с разработками М. А. Усова, Г. Шнейдерхёна, В. А. Кузнецова, Р. М. Константинова и др. названа группа месторождений со сходными по составу минеральными ассоциациями и близкими геологическими условиями образования. Определяющий признак отнесения месторождения к той или иной формации - состав минеральных ассоциаций; геологические условия образования, к сожалению, нередко подменяются только физико-химическими условиями рудоотложения (например, больших, умеренных или малых глубин). А поскольку состав минеральных ассоциаций в значительной мере зависит от физикохимических условий рудообразования, то термин «формация» приобрел в основном физикохимическое содержание.

Базовые рудные формации (рис. 1,a), определяющие минералого-геохимический состав каждого иерархического ряда сателлитов (рис. $1, \sigma)$, сравнительно немногочисленны (от 10-12 в крупных рудных провинциях до 1-3 в рудном районе). При этом оказалось необходимым ввести понятия простого и сложного (полихронного) рядов. Простой (монохронный) ряд, типа медно-порфирового, характеризуется тесными близкими во времени парагенетическими связя- ми всех месторождений с едиными источниками рудного вещества. В сложном полихронном ряду месторождения связаны как генетически через реювенацию (регенерацию) ранних образований, так и парагенетически.

Базовое месторождение - это иерархическое начало ряда, построенного в соответствии с общими принципами рудообразования: от сложных комплексных месторождений к простым, предельно дифференцированным, до монометалльных включительно. Последние, как правило, являются конечными (завершающими) членами ряда. Вместе с тем базовое месторождение в полихронном ряду по мере выявления более многокомпонентных и более древних месторождений может утратить свое начальное (крайнее) место. Комплексные месторождения, отнесенные нами к базовым рудным формациям, отчетливо разделяются на три группы (рис. 2). При этом месторождения второй и третьей групп нередко (но далеко не всегда) сопровождают первую группу. Ряд конкретных рудных формаций обосновывается стадийностью (этапностью) рудоотложения. При этом базовое месторождение либо надстадийно (рудное вещество наиболее слабо дифференцировано), либо характеризуется рудами с максимальным количеством стадийных минеральных ассоциаций. В месторождениях, завершающих ряды, количество минеральных ассоциаций минимально.

Основная цель статьи - показать, что в рудноформационном анализе дивергентные явления распространены не менее, чем конвергентные. Выполненные исследования соотношения дивергенции и конвергенции в рудообразовании направлены на дальнейшее развитие РА. $a$

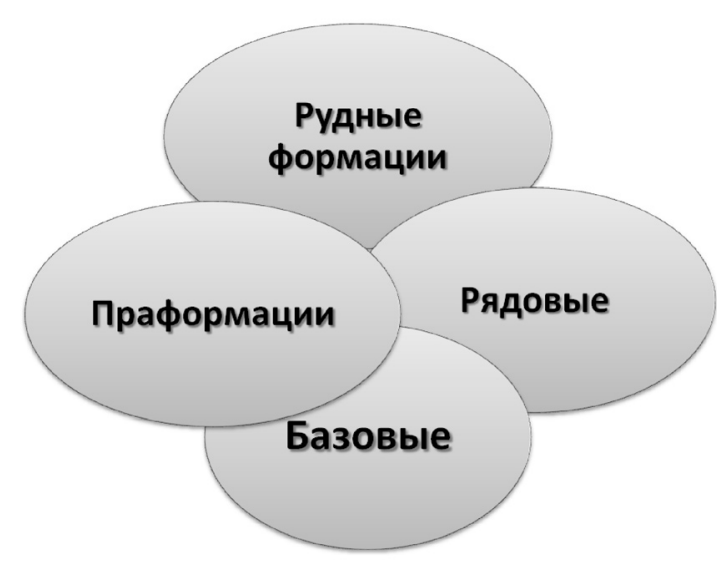

Puc. 1. Виды рудных формаций $(a)$ и рудноформационных рядов (б)

Fig. 1. Types of ore formations $(a)$ and ore formation series $(\sigma)$

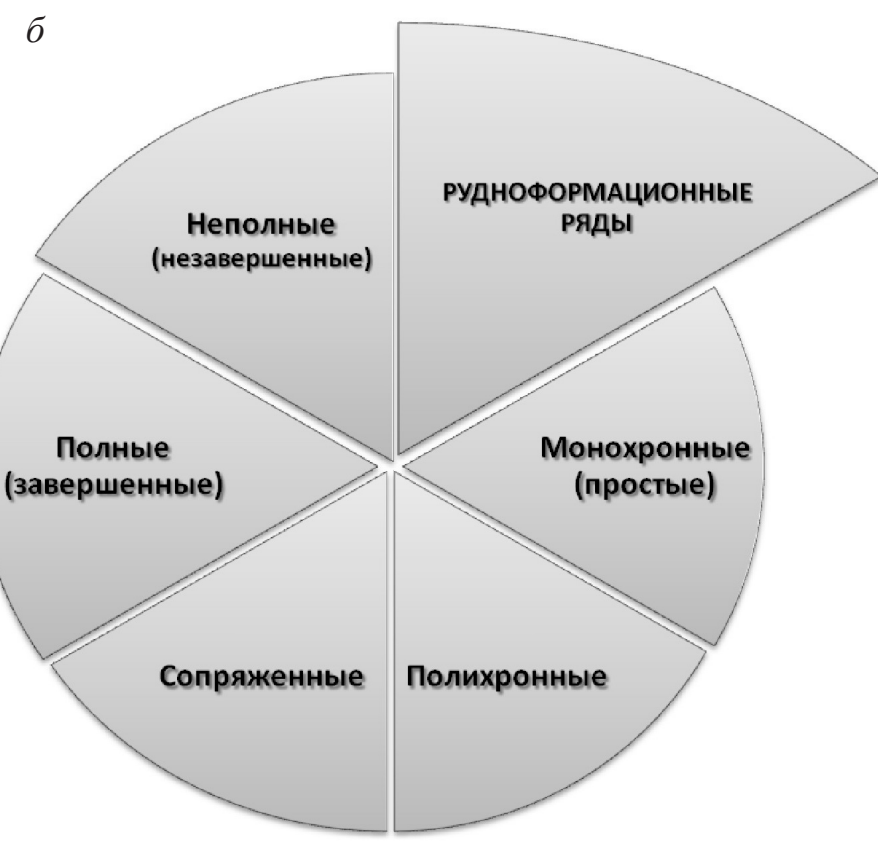




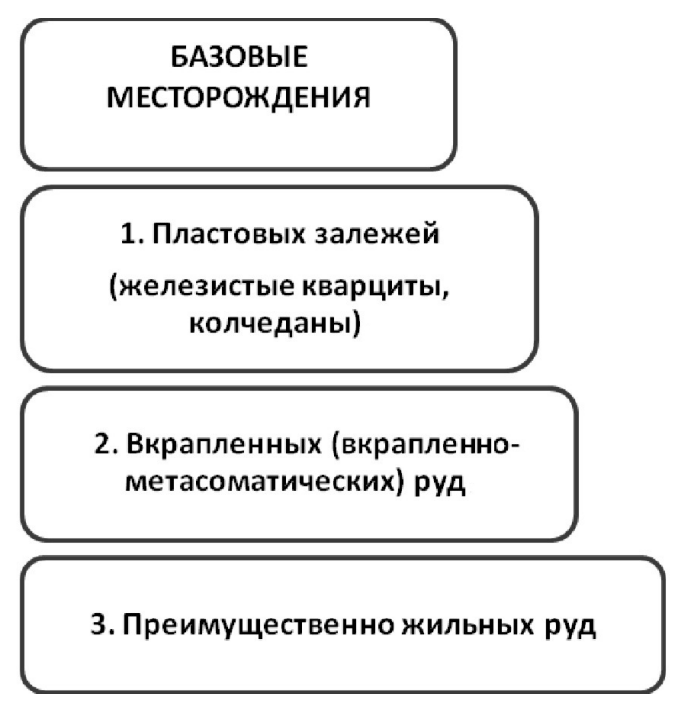

Puc. 2. Группы базовых рудных месторождений

Fig. 2. Groups of major ore deposits

\section{О КОНВЕРГЕНЦИИ И ДИВЕРГЕНЦИИ В РУДООБРАЗОВАНИИ}

Начальная идея формационного ряда была заложена еще в древнем проспекторском афоризме: «ищи руду около руды». Наши исследования позволили установить высокую конвергентность эпитермальных месторождений различных рудноформационных рядов (железисто-кварцитовых, колчеданных сульфидных вкрапленных, порфировых) с разнообразными источниками минерального вещества (Сидоров, Волков, 2004). Конвергентность этих, а затем и многих других месторождений (Волков, Сидоров, 2005, 2016) объяснялась близкими физико-химическими условиями отложения минеральных ассоциаций, возникающих в различных геодинамических (тектоно-металлогенических) обстановках, что хорошо демонстрирует несостоятельность всех якобы генетических систематик рудных месторождений.

Зародившийся в биологии термин «конвергенция» получил определенное распространение в научных отраслях геологии. Но почти не применяется другой биологический термин, с гораздо большей тщательностью разработанный в трудах Дарвина. Это «дивергенция» - изменение вида под воздействием среды (Геологический словарь, 1978). Дивергенция в Геологическом словаре (1978) также определена по Дарвину.

Впрочем, нередко эти термины разными исследователями используются противоречиво. Эвристически ценным представляется сформулированное Г. Л. Поспеловым понятие конвергентной неопределенности: «Если некоторый набор характерных генетических признаков явления (типовых свойств, взаимосвязей и т. д.) оказывается конвергентным по отношению к двум или нескольким генетическим процессам, то генетическое решение вопроса в пределах данного набора становится принциииильно неопределеннылм (1963. C. 265).

Наше понятие конвергенции в рудообразовании, как уже говорилось, рассмотрено в ряде работ, в том числе в монографии (Сидоров и др., 2011). Но что же такое дивергенция в рудообразовании? Наиболее ярко она проявлена в субмаринных вулканогенных поясах по сравнению с их аналогами в окраинноконтинентальных структурах. В частности, $\mathrm{Cu}$-порфировые руды по своему составу близки рудам «око, куроко и кейко», хотя по морфологии и структурному положению ничего общего не имеют с пластовыми залежами. Вместе с тем по своему положению в структурах смежных вулканогенных поясов (окраинноматериковый и околоконтинентальный - субмаринный) можно с определенной долей вероятности сделать заключение о родстве глубинных источников руд этих формационных типов. Иными словами, если в окраинноматериковых вулканогенных структурах мы имеем значительное количество $\mathrm{Cu}$-порфировых месторождений, то в смежных структурах субмаринной природы есть все основания ожидать колчеданные залежи типа Куроко. Таких примеров можно найти множество. И мы предлагаем назвать это явление дивергентностью вулканогенного рудообразования.

Элементы конвергентности (подобия) состава этих рядов обусловлены близкими физикохимическими условиями формирования порфировых и эпитермальных месторождений. Базовые формации, напротив, демонстрируют генетическое разнообразие оруденения (табл. 1), что подтверждается также близкими отношениями изотопов свинца в рудах различных минеральных типов одного района и разными отношениями этих изотопов в рудах однотипных месторождений разных районов (Сидоров, Волков, 2004).

Сравнительный анализ, прежде всего, обращает внимание на исчезновение оловянных месторождений во внутренней зоне Охотско-Чукотского вулканогенного пояса (ОЧВП), хотя отдельные проявления Sn-Ag-порфировых руд здесь зафиксированы. Вместе с тем более «меденосный» характер этой зоны очевиден, что, по всей вероятности, связано с островодужным основанием вулканогенных зон. Во внешней зоне фундамент в отличие от внутренней зоны представлен мощными оловоносными толщами верхоянского комплекса. Отмеченное выше позволяет предположить, что во внутренней зоне ОЧВП весьма реальны перспективы открытия новых колчеданных месторождений (типа Куроко) и их сателлитов. 
Таблица. 1. Примерная дивергентно-конвергентная систематика рудных месторождений Северо-Востока России

Table. 1. Approximate divergent-convergent systematics of ore deposits in the North-East of Russia

\begin{tabular}{|c|c|c|c|c|c|c|c|}
\hline \multirow{3}{*}{$\begin{array}{c}\text { Ряды (названы } \\
\text { по базовым руд- } \\
\text { ным формациям) }\end{array}$} & \multicolumn{7}{|c|}{$\begin{array}{c}\text { Группы жильных и прожилково-вкрапленных месторождений } \\
\text { Глубины и температура рудообразования } \\
\end{array}$} \\
\hline & Больших глубин & \multicolumn{3}{|c|}{\begin{tabular}{|l} 
Умеренных глубин \\
\end{tabular}} & \multicolumn{3}{|c|}{ Малых глубин } \\
\hline & высокая & высокая & средняя & низкая & высокая & средняя & низкая \\
\hline $\begin{array}{l}\text { Cu-Ni- сульфид- } \\
\text { ный }\end{array}$ & $\begin{array}{l}\text { Зоны вкрапленной } \\
\mathrm{Cu}-\mathrm{Ni} \text {-сульфидизации, } \\
\text { залежи массивных Cu- } \\
\text { Ni руд } \\
\end{array}$ & $\begin{array}{l}\text { Порфировые } \\
\mathrm{Cu}-\mathrm{Au}\end{array}$ & \multicolumn{2}{|c|}{$\begin{array}{l}\text { Жильные Cu-Ag-Pb- } \\
\mathrm{Zn}\end{array}$} & \multicolumn{3}{|c|}{$\begin{array}{l}\text { Эпитермальные жильные } \\
\text { Au-Te, Au-Ag-Te }\end{array}$} \\
\hline $\begin{array}{l}\text { Fе-кварцито- } \\
\text { вый }\end{array}$ & $\begin{array}{l}\text { Скарновые магнетит- } \\
\text { кварцевые, зоны } \\
\text { сульфидизации и } \\
\text { кварцево-рудные жилы }\end{array}$ & \multicolumn{3}{|c|}{$\begin{array}{l}\text { Жильные сульфидно-полиметалли- } \\
\text { ческие и золоторудные }\end{array}$} & \multicolumn{3}{|c|}{$\begin{array}{l}\text { Эпитермальные жильные } \\
\text { Au-Ag-Te, Au-Ag }\end{array}$} \\
\hline Колчеданный & $\begin{array}{l}\text { Месторождения отсут- } \\
\text { ствуют }\end{array}$ & $\begin{array}{l}\text { Порфировые } \\
\mathrm{Cu}-\mathrm{Ag}, \mathrm{Sn}-\mathrm{Ag}\end{array}$ & \multicolumn{2}{|c|}{$\begin{array}{l}\text { Жильные полиметал- } \\
\text { лические и золото- } \\
\text { рудные }\end{array}$} & \multicolumn{3}{|c|}{$\begin{array}{l}\text { Эпитермальные жильные } \\
\text { Au-Ag }\end{array}$} \\
\hline $\begin{array}{l}\text { Сульфидный, } \\
\text { вкрапленных } \\
\text { руд }\end{array}$ & $\begin{array}{l}\text { Зоны сульфидизации } \\
\text { различной природы, } \\
\text { кварцево-рудные жилы }\end{array}$ & \multicolumn{3}{|c|}{$\begin{array}{l}\text { Зоны сульфидизации различной } \\
\text { природы, кварцево-рудные жилы } \\
\text { от золотоносных до оловоносных }\end{array}$} & \multicolumn{3}{|c|}{$\begin{array}{l}\text { Эпитермальные жильные } \\
\text { Au-Ag и метасоматические } \\
\text { рудные залежи }\end{array}$} \\
\hline
\end{tabular}

В сущности, наши рудноформационные ряды (Сидоров и др., 2011) дивергентно-конвергентны, так как формирование месторождений этих рядов определяется физико-химическими условиями отложения руд, а различие рядов тесно связано с источниками минерального вещества. Именно поэтому каждый ряд возглавляется базовым месторождением (Fe-кварцитовым, колчеданным, сульфидным тонковкрапленным, порфировым) и характеризует металлогению различных рудных районов. Отдельные месторождения в этих рядах конвергентны (например, эпитермальные, которые всегда формируются в близповерхностных преимущественно низкотемпературных условиях), другие месторождения рядов также обладают разной степенью конвергентности.

Элементы родства рядов представлены не только близким порядком расположения рудньх парагенезисов (от высокотемпературных к низкотемпературным), но и тесной связью с базовыми месторождениями каждого ряда. Базовые месторождения - это не только важный указатель источников рудогенных элементов, но и нередко источник таковых для других месторождений рядовых формаций.

Недооценка дивергентно-конвергентных явлений часто приводила к длительным заблуждениям. В частности, в американской литературе многие кварцевые жилы определялись по учению Дж. Сперра (1933) магматическими до развития учения о микровключениях - газо-жидких при образовании кварца из гидротермальных растворов и расплавных в магматическом кварце. Длительное время многие геологи, в том числе и такие наши классики, как С. С. Смирнов и Ю. А.
Билибин, связывали источники эпитермальных руд с некими однотипными глубинными очагами (Смирнов, 1955; Билибин, 1961), хотя мы по мере развития рудноформационного анализа и изотопных исследований со всей очевидностью показали их разнообразную коровую природу (Сидоров и др., 2011).

Однако необходимость изучения дивергенции и конвергенции становится особенно очевидной при создании и совершенствовании систематик (классификаций) минеральных ассоциаций и рудных месторождений; негенетичность нынешних классификаций месторождений вполне обоснованно признается, в частности, в Геологическом словаре (1978).

Дивергентность и конвергентность рудноформационных рядов существенно приближает нас к повышению познаний именно генетичности месторождений, т. е. к определению источников рудогенных элементов даже при самой высокой конвергентности физико-химических процессов отложения минеральных ассоциаций. Более того, сами члены ряда (базовые месторождения) нередко являются источниками минеральных ассоциаций для рядовых членов ряда, входящих в соответствующие группы. В последних, как уже отмечалось, распространены месторождения различной степени конвергентности. Отметим также, что в гениальной Периодической системе элементов Д. И. Менделеева хорошо видны проявления конвергенции в группах и признаки дивергенции в периодах.

На принципах этой систематики (см. табл. 1) нами была разработана более глобальная примерная систематика (табл. 2). 
Таблица. 2. Дивергентно-конвергентная систематика рудных месторождений конкретных районов Table. 2. Divergent-convergent systematics of ore deposits in the specific districts

\begin{tabular}{|c|c|}
\hline $\begin{array}{c}\text { Ряды и примеры рудных } \\
\text { районов } \\
\end{array}$ & $\begin{array}{c}\text { Группы и наименования рудных формаций } \\
\text { (базовые формации - полихронные - жирный шрифт; монохронные - курсив) }\end{array}$ \\
\hline $\begin{array}{l}\text { Cu-Ni } \\
\text { (Бушвельд, Ю. Африка; } \\
\text { Норильск) }\end{array}$ & $\begin{array}{c}\text { Медно-никелевая и платинометалльная, медно-колчеданная, } \\
\qquad u(M o) \text {-порфировая, } A u \text {-порфировая, } \mathrm{Au}(\mathrm{Ag})-\mathrm{Te}, \mathrm{W}-\mathrm{Hg}\end{array}$ \\
\hline $\begin{array}{l}\mathbf{C r} \\
\text { (Бушвельд; Корякия) }\end{array}$ & Хромитовая и платинометалльная, $A$-порфировая, $\mathrm{Au}-\mathrm{Te}, \mathrm{W}-\mathrm{Hg}$ \\
\hline $\begin{array}{l}\text { Pg-rr } \\
\text { (Волынь, Украина) }\end{array}$ & Пегматитовая редкометалльная и редкоземельная, $\mathrm{Be}, \mathrm{Mo}-\mathrm{W}, \mathrm{Nb}-\mathrm{Ta}-\mathrm{U}$ \\
\hline $\begin{array}{l}\text { Cu(Mo)-Por } \\
\text { (Бингем, США; } \\
\text { Песчанка, Чукотка) }\end{array}$ & $\begin{array}{c}\text { Cu(Mo)-nорфировая, Аu-nорфировая, скарново-полиметаллическая, жильная поли- } \\
\text { металлическая, } \mathrm{Au}-\mathrm{Ag}, \mathrm{Sb}-\mathrm{Hg}, \mathrm{Hg}\end{array}$ \\
\hline $\begin{array}{l}\text { Sn(Ag)-Por } \\
\text { (Потоси, Боливия; } \\
\text { Омсукчан, Россия) }\end{array}$ & $\begin{array}{l}\mathrm{Sn}(\mathrm{Ag}) \text {-порфировая, грейзено-редкометалльная, касситерит-силикатно-сульфидная, } \\
\text { Sn-полиметаллическая, } \mathrm{Sn}-\mathrm{Ag}, \mathrm{Au}-\mathrm{Ag} \text { (существенно Ag), Sb }\end{array}$ \\
\hline $\begin{array}{l}\text { Au-Por } \\
\text { (Центр. Колыма) }\end{array}$ & Аи-порфировая, Аu-сульфидно-кварцевая, $\mathrm{Au}-\mathrm{Ag}, \mathrm{Sb}, \mathrm{Sb}-\mathrm{Hg}$ \\
\hline $\begin{array}{l}\text { Cu, Zn-sd } \\
\text { (Норанда, Канада) }\end{array}$ & Медно-колчеданная (тип Норанда), Cu-nорфировая, Au-nорфировая, $\mathrm{Au}(\mathrm{Ag})-\mathrm{Te}$ \\
\hline $\begin{array}{l}\text { Pb, Zn-sd } \\
\text { (Куроко, Япония) }\end{array}$ & $\begin{array}{c}\text { Колчеданная полиметаллическая, } \mathrm{Au} \text {-порфировая, жильная полиметаллическая, } \\
\mathrm{Au}-\mathrm{Ag}, \mathrm{Sb}, \mathrm{Hg}\end{array}$ \\
\hline $\begin{array}{l}\text { Au, Q-sd } \\
\text { (Центр. Колыма, Чукотка) }\end{array}$ & $\begin{array}{c}\text { Аи-кварц-сульфидная (вкрапленных руд), Au-nорфировая, } \mathrm{Au-кварцевая.} \\
\text { Касситерит-кварц-сульфидная (вкрапленных руд), } \operatorname{Sn}(\mathrm{Ag}) \text {-порфировая, } \\
\text { вольфрамит-касситерит-кварцевая, касситерит-силикатно-сульфидная, } \mathrm{Sb}\end{array}$ \\
\hline $\begin{array}{l}\text { Sk-sd } \\
\text { (Восточное Забайкалье) }\end{array}$ & $\begin{array}{c}\text { Шеелит-сульфидно-скарновая, W-полиметаллическая, } \mathrm{Sn}-\mathrm{W}, \mathrm{Au}-\mathrm{Cu}(\mathrm{Mo})-\mathrm{W}, \\
\text { W-редкометалльная }\end{array}$ \\
\hline $\begin{array}{l}\text { Au-sd } \\
\text { (Майский, Чукотка) }\end{array}$ & $\begin{array}{c}\text { Аи-сульфидная (вкрапленных руд), Аu-порфировая, } \mathrm{Au-сульфидно-кварцевая,} \mathrm{Au-} \\
\text { кварцевая, } \mathrm{Au}-\mathrm{Ag}, \mathrm{Sb}, \mathrm{Hg}\end{array}$ \\
\hline $\begin{array}{l}\text { Ag-sd } \\
\text { (Дукатский, Россия) }\end{array}$ & 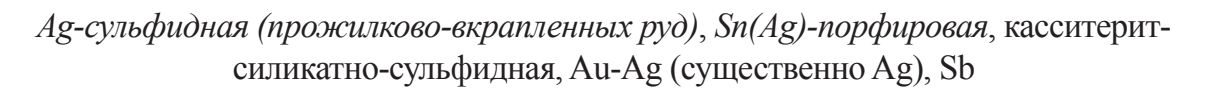 \\
\hline $\begin{array}{l}\text { W-q-sd } \\
\text { (Центр. Колыма) }\end{array}$ & $\begin{array}{c}\text { Шеелит-сульфидно-кварцевая стратиформная, } \mathrm{Sn}(W) \text {-nорфировая, жильная по- } \\
\text { лиметаллическая, } \mathrm{Au}-\mathrm{Ag}\end{array}$ \\
\hline $\begin{array}{l}\mathbf{P b}, \mathbf{Z n} \\
\text { (Омулевский, Россия) }\end{array}$ & $\begin{array}{c}\text { Полиметаллическая стратиформная, шеелит-скарновая, } A u(A g) \text {-порфировая, } \\
\operatorname{Sn}(W) \text {-порфировая }\end{array}$ \\
\hline $\begin{array}{l}\text { U-Mе } \\
\text { (Олимпик-Дам, Австралия) }\end{array}$ & $\begin{array}{l}\text { U-многометалльные (Cu-песчаники и сланцы, другие стратиформные), скар- } \\
\text { новьле редкометалльные и редкоземельньле, пятиэлементная, полиметаллические } \\
\text { стратиформные и жильные, } \mathrm{Sn} \text { - W, } \mathrm{Sn}(\mathrm{Ag}) \text {-порфировая, } \mathrm{Au-nорфировая,} \mathrm{Au}-\mathrm{Ag}, \mathrm{Sb}\end{array}$ \\
\hline $\begin{array}{l}\text { Fe } \\
\text { (Исуа, Гренландия) }\end{array}$ & $\begin{array}{l}\text { Железисто-кварцитовая, колчеданные, скарновая магнетитовая, редкоземельные, } \\
\qquad A u \text {-порфировая, Аu-кварцевая, } \mathrm{Au}-\mathrm{Ag}\end{array}$ \\
\hline $\begin{array}{l}\text { Fe, Mn } \\
\text { (М. Хинган, Россия) }\end{array}$ & ая, скарновая магнетитовая, редкоземельная \\
\hline
\end{tabular}

Напомним также, что неоднократно показано в наших трудах (Сидоров и др., 2011; Волков и др., 2014), что базовые месторождения (формации) могут быть изменены по мере изучения региона или рудного района и только одно в них неизменно - это всегда крупнейшие рудные месторождения.

Подобные систематики в конкретных и металлогенических провинциях, а также в крупных рудных районах могут нести элементы прогнозирования новых месторождений. В частности, широкое развитие минералов $\mathrm{Sb}$ и $\mathrm{Hg}$ в базовых месторождениях, рассматриваемых как преимущественно золотоносные, служит важным указателем наличия в этих районах $\mathrm{Hg}$ и $\mathrm{Sb}$ месторождений. И наоборот, даже невысокая золотоносность руд этих месторождений свидетельствует о возможности открытия в районах новых золоторудных месторождений. 


\section{ЗАКЛЮЧЕНИЕ}

В заключение отметим, что РА, несмотря на исчезающие отечественные школы по геологии рудных месторождений, таит особые возможности для научного понимания генезиса месторождений и практического освоения новых и старых почти всегда недоизученных рудных районов. Ранее мы исследовали наши ряды с позиций онтогенеза и филогенеза (Сидоров, Волков, 2016) и убедились, что многие методы изучения биологических систем вполне приемлемы при рассмотрении особенностей рудообразования.

В результате построения дивергентно-конвергентных моделей рудных полей, районов и крупных регионов мы полагаем, что они не только служат пересмотру и улучшению существующих систематик месторождений, но и необходимы при освоении сложных базовых месторождений и их разнообразных сателлитов, рассматриваемых обычно в качестве самостоятельных рудных формаций.

Работа выполнена по теме Госзадания ИГЕМ РАН «Металлогения рудных районов вулканоплутоногенных и складчатых орогенных поясов Северо-Востока России»

\section{ЛИТЕРАТУРА}

Билибин Ю. А. Металлогенические провинции и металлогенические эпохи // Избр. тр. М. : Изд-во АН CCCP, 1961. T. 3. С. 67-130.
Волков А. В., Сидоров А. А., Старостин В. И. Металлогения вулканогенных поясов и зон активизации. М. : ООО «МАКС Пресс», 2014. 355 с.

Волков А. В., Сидоров А. А. Тектоно-металлогенические обстановки формирования и конвергентность Аu-сульфидного оруденения // ДАН. 2016. T. 469, № 5. С. 582-586.

Волков А. В., Сидоров А. А. Этапы формирования и конвергенция золото-кварцевого оруденения СевероВостока России // ДАН. 2005. Т. 401, № 1. С. 52-57.

Геологический словарь. М. : Недра, 1978. Т. 2. 486 с.

Поспелов Г. Л. О проблеме конвергенции в петрографии и геологии // Проблемы магм и генезиса изверженных горных пород. М. : Изд-во АН СССР, 1963. C. 260-271.

Сидоров А. А., Волков А. В. Генетическое разнообразие и конвергенция эпитермального золотосеребряного оруденения // ДАН. 2004. Т. 397, № 1. C. $72-77$.

Сидоров А. А., Волков А. В. Проблемы онтогенеза и филогенеза руд // Вестник РАН. 2016. Т. 86, № 1. C. $30-35$.

Сидоров А. А., Старостин В. И., Волков А. В. Рудноформационный анализ. М. : МАКС Пресс, 2011. 177 с.

Смирнов С. С. Избранные труды. М. : Изд-во АН CCCP, 1955. $248 \mathrm{c}$.

Cnерр Дж. Е. Рудные магмы // Новые идеи в учении о рудных месторождениях / под ред. И. Ф. Григорьева. М. : ОНТИ НКТП СССР, 1933. Сер. 3. Вып. 5. C. 6-69.

Хаин В. Е., Ломизе М. Г. Геотектоника с основами геодинамики. М. : Изд-во МГУ, 1995. 476 с.

Шатский Н. С. Избранные труды. М. : Наука, 1964. T. 2. 420 c.

\title{
DIVERGENCE AND CONVERGENCE IN THE ORE FORMATION ANALYSIS
}

\author{
A. A. Sidorov, A. V. Volkov \\ Institute of Geology of Ore Deposits, Petrography, Mineralogy and Geochemistry, \\ RAS, Moscow
}

In ore formation analysis (OFA), divergent phenomena are not less common than convergent. Unlike in biology, in the OFA divergence means a fundamental diversity of ore assemblage series. Thus, the authors consider series to be divergent, and combine the deposits in them, with elements of similarity in the PT-conditions of mineral association deposition, into groups with different degrees of convergence (small, moderate. and large depths and temperatures). Each series is headed by a basic ore assemblage, which reflects the elements of ordinary deposits, often in the form of stage mineral associations. On the basis of this concept, prognostic ore formation series of deposits can be proposed not only in the metallogenic provinces but also within certain ore districts.

Keywords: divergence, convergence, ore formation, ore deposit, ore formation series, genesis, forecast. 


\section{REFERENCES}

Bilibin, Yu. A., 1961, Metallogenic Provinces and Metallogenic Epochs, Selected Works, Moscow, Izd-vo AN SSSR, 3, 67-130 [In Russian].

Geological Dictionary, 1978, Moscow, Nedra, 2 [In Russian].

Khain, V. E.; Lomize, M. G., 1995, Geotectonics with the Foundations of Geodynamics, Moscow, Izd-vo MGU [In Russian].

Pospelov, G. L., 1963, On the Problem of Convergence in Petrography and Geology, Problems of Magmas and Genesis of Igneous Rocks, Moscow, Izd-vo AN SSSR, 260-271 [In Russian].

Shatsky, N. S., 1964, Selected Works, Moscow, Nauka, 2 [In Russian].

Sidorov, A. A.; Volkov, A. V., 2004, Genetic Diversity and Convergence of Epithermal Gold-Silver Mineralization, Doklady Akademiyi Nauk, 397, 1, 72-77 [In Russian].

Sidorov, A. A.; Volkov A. V., 2016, Problem of Ore Ontogenesis and Phylogenesis, Vestnik RAN, 86, 1, 30-35 [In Russian].
Sidorov A. A.; Starostin V. I.; Volkov A. V., 2011, Ore Formation Analysis, Moscow, MAX Press [In Russian].

Smirnov, S. S., 1955, Selected Works, Moscow, Izd-vo AN SSSR [In Russian].

Spurr, J. E., 1933, Ore Magmas, New Ideas in the Ore Deposit Theory, Ed. I. F. Grigoryev, Moscow, ONTI NKTP SSSR, 3, Iss. 5, 6-69 [In Russian].

Volkov, A. V.; Sidorov, A. A., 2005, Stages of Formation and Convergence of Gold-Quartz Mineralization in the North-East of Russia, Doklady Akademiyi Nauk, 401, 1, 52-57 [In Russian].

Volkov, A. V.; Sidorov, A. A., 2016, TectonicMetallogenic Conditions of Formation and Convergence of Au- Sulfide Mineralization, Ibid., 469, 5, 582-586 [In Russian]

Volkov, A. V.; Sidorov, A. A.; Starostin, V. I., 2014, Metallogeny of Volcanic Belts and Activation Zones, Moscow, MAX Press [In Russian]. 